Título da exposição: Observações Visuais Reflexivas 1

Autor(es): Milton Guran

Agência(s) Financiadora(s) da Navisual/PPGAS

Exposição:

Pesquisa e Instituição: Museu do Índio do Rio de Janeiro

Cidade e Data da Pesquisa: Mato Grosso, 1986

Paraná, 1987

Pará, 1989

Amazonas, 1989 e 1991

Roraima, 1991

Local da exposição: Galeria Olho Nu, IFCH, UFRGS, Porto Alegre, RS.

Período da exposição: 24 de março a 5 maio de 2014

Curadoria: Milton Guran

Coordenação de montagem: Fabricio Barreto

Equipe de montagem: Aline Renner, Cedric, Débora Wobeto, Fabiela Bigossi, Jonathan Madeira, Junior Abalos, Letícia Rodrigues, Roberta Simon, Rumi Kubo, Yuri Rapkiewicz.

Profa. Dra. Cornelia Eckert - PPGAS/UFRGS

Coordenação geral:

Ficha técnica: 8 fotos tamanho $30 \times 45 \mathrm{~cm}, 4$ fotos tamanho $40 \times 60 \mathrm{~cm}$. Impressão jato de tinta em adesivo colado em PVC

Equipamento: Analógico, filme preto e branco

Forma de citação da resenha: BARRETO, Fabricio. Observações Visuais Reflexivas 1. Revista Iluminuras [on line], Porto Alegre, v 15, $n^{\circ} 35$

\title{
“OBSERVAÇÕES VISUAIS REFLEXIVAS 1": UM EXERCÍCIO EXPOGRÁFICO SOBRE A COLEÇÃO DE MILTON GURAN
}

\section{Fabricio Barreto ${ }^{1}$}

Esta resenha tem o propósito de reconstruir como foram os desdobramentos de apresentação da exposição fotográfica "Observações Visuais Reflexivas 1" de Milton Guran na Galeria Olho $\mathrm{Nu} 2$, e assim compartilhar a experiência e o processo desta atividade realizada pelo Núcleo de Antropologia Visual (NAVISUAL) da UFRGS.

\footnotetext{
${ }^{1}$ Universidade Federal do Rio Grande do Sul, Brasil.

2 A Galeria Olho $\mathrm{Nu}$ está localizada no IFCH - UFRGS e tem por propósito a divulgação de material, em geral fotográfico, produzido em pesquisas acadêmicas desenvolvidas no Instituto. Hoje, a galeria tem por curadores os pesquisadores vinculados ao NAVISUAL. Sua perspectiva curatorial está voltada para a divulgação da produção imagética em antropologia visual para o público especialista e leigo que frequenta o Campus do Vale.
}

Iluminuras, Porto Alegre, v. 15, n. 35, p. 438-450, jan./jul. 2014 
Desta forma procuro acentuar a importância de se estabelecer a prática de apresentação de exposições etnográficas, visando aproximar tanto a comunidade acadêmica como o público em geral das pesquisas realizadas pela Antropologia. Portanto, não só como ferramenta de restituição, a exposição etnográfica assume também o papel de aproximação de áreas afins, fomentando a partilha do conhecimento científico.

Nosso ilustre convidado é doutor em Antropologia pela École des Hautes Études en Sciences Sociales (França, 1996). No início de sua carreira, trabalhou como repórterfotógrafico em Brasília (1980), quando foi um dos fundadores da Ágil (Agência Imprensa Livre). Ganhou o Prêmio Vitae (1990), o X Prêmio Marc Ferrez da FUNARTE (1998) e o Prêmio Pierre Verger da Associação Brasileira de Antropologia (2002). Em 2012, foi agraciado com a comenda da Ordem Nacional do Mérito. Atualmente é professor titular da Universidade Federal Fluminense e pesquisador do LABHOI - Laboratório de História Oral e Imagem.

A coleção de imagens exposta na Galeria Olho $\mathrm{Nu}$ são do final da década de 80 e início dos anos 90, período em que o fotógrafo, então mestrando em comunicação pela UNB (Universidade de Brasília) trabalhava para o Museu do Índio do Rio de Janeiro. Elas apresentam representantes de diferentes etnias indígenas do Brasil e foi primeiramente elaborada para compor a exposição "Filhos da Terra", apresentada no ano passado no Centro Cultural dos Correios do Rio de Janeiro. Lá a exposição contava com 58 imagens. Para a Olho Nu, Guran fez uma seleção de 12 fotografias.

\section{Pré-produção}

Em setembro de 2013 convidamos o professor Milton Guran a proferir uma palestra na UFRGS para os alunos de Ciências Sociais e comunidade interessada. A palestra faria parte do programa de atividades realizadas em comemoração aos 40 anos do Programa de Pós-graduação da Antropologia Social, ocorrido em março de 2014. Aceito o convite para a palestra, surgiu-nos a ideia de convidá-lo a expor e prestigiar nossa estimada Galeria Olho Nu. A partir daí, foram diversas trocas de mensagens a fim de ajustar os detalhes da montagem, tais como o tipo de papel no qual imprimiríamos as imagens, a 

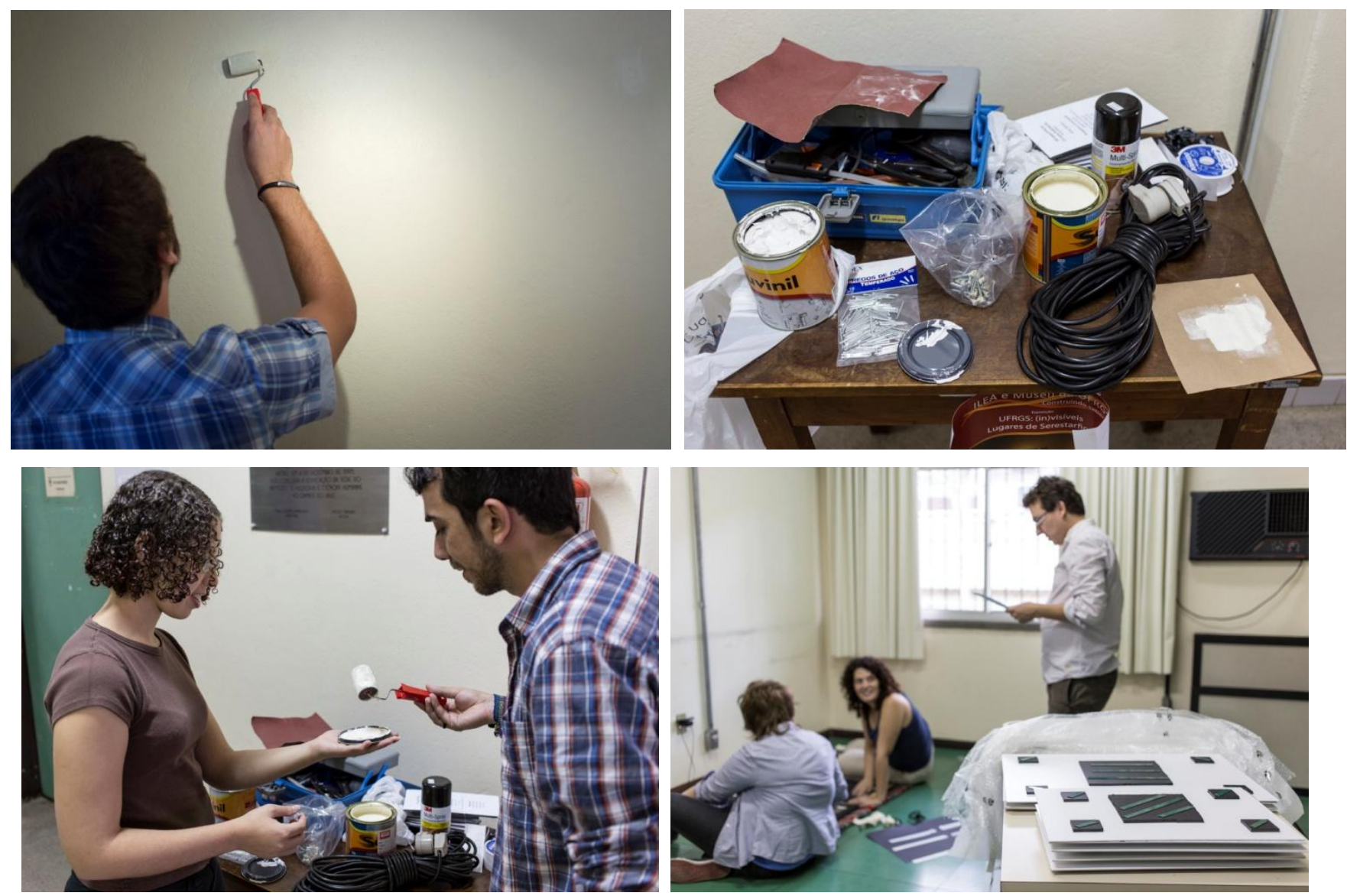

Fotos Fabricio Barreto

forma de fixação das fotografias nas paredes, o texto de apresentação da exposição, cartazes, flyers, cronograma de atividades, etc. Enviamos fotos da galeria ao Guran, para que ele pudesse dimensionar o espaço a ser ocupado. Nosso planejamento incluía a realização da pré-produção antes da chegada do nosso convidado a Porto Alegre, para que, junto com ele, montássemos a exposição na galeria.

Todo processo de elaboração foi compartilhado com o grupo do Navisual, e aqueles que puderam participar, tiveram a oportunidade de compreender o passo-apasso da pré-produção de uma exposição fotográfica. A próxima etapa contaria com a presença do coordenador-geral e realizador do FOTORIO ${ }^{3}$

\footnotetext{
3 Encontro Internacional de Fotografia, do Rio de Janeiro, coordenado por Milton Guran. http://www.fotorio.fot.br
} 


\section{Montagem da exposição}

A montagem de uma exposição não é tarefa fácil. Requer uma capacidade de prever as dificuldades que enfretaremos ao colocar as fotografias em exposição. Essas dificuldades podem ser relativas à altura das imagens em relação ao chão, a que distância estarão umas das outras, a disposição destas no espaço da galeria, como a iluminação do espaço vai funcionar, o alinhamento para que não fiquem tortas. Todos estes cuidados estão relacionados à comunicação que a exposição fará com seus espectadores e como queremos que esta comunicação aconteça para transmitir aquilo que queremos. Muitas vezes elaboramos croquis para que possamos pensar com antecipação que lugar cada uma das fotografias ocupará. Procuramos imaginar ou até
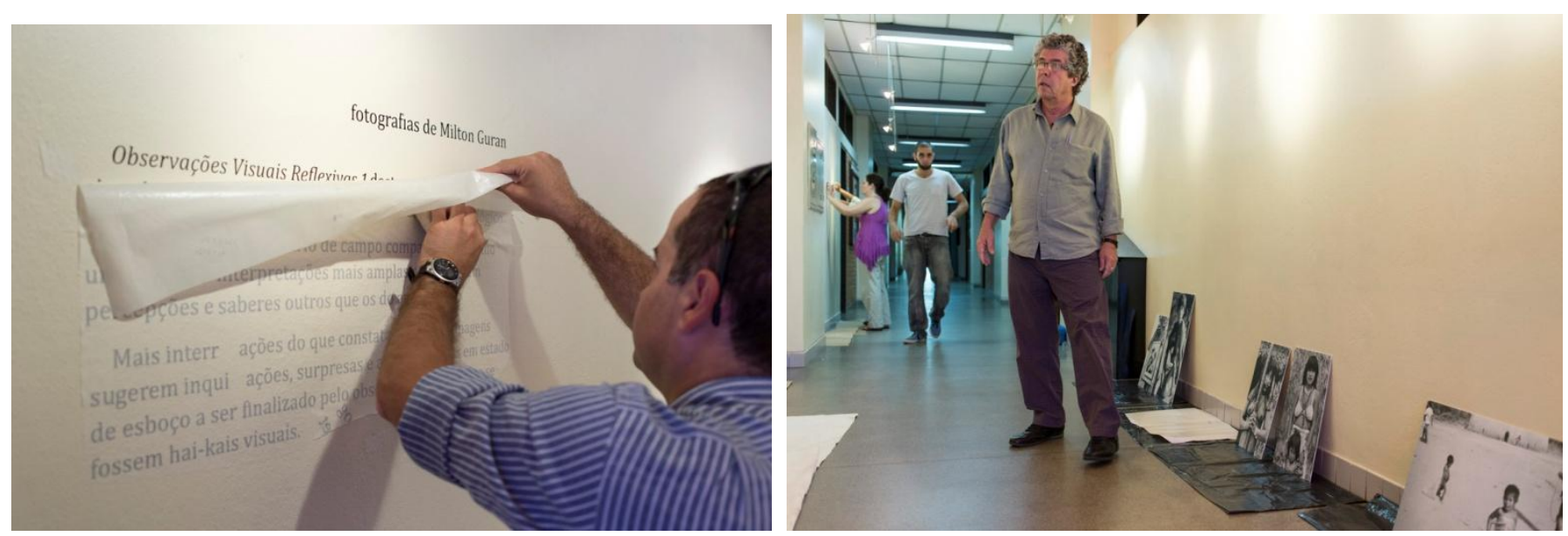

Fotos Fabricio Barreto

mesmo conduzir qual o trajeto que o olhar do espectador realizará ao visitar a exposição e até mesmo como podemos direcionar este olhar. Assim estaremos nos cercando de maiores possibilidades de transferir da forma mais eficiente a informação que queremos passar.

Um aspecto importante adotado pelo professor Guran para esta exposição, foi a não utilização de textos-legendas que explicassem as fotos. Durante a troca de mensagens para ajustes da montagem, perguntei se gostaria de usar legendas e como seriam apresentadas. Ele respondeu que optou por não utilizar texto para explicar cada 

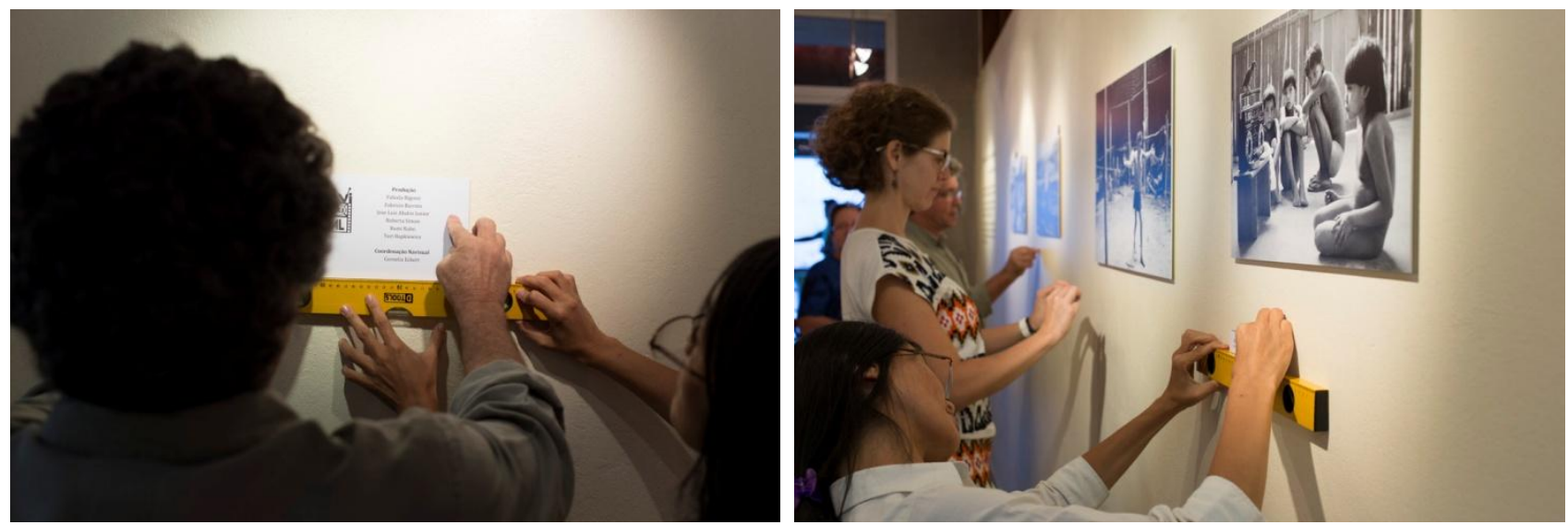

Fotos Fabricio Barreto

uma das fotos, pois assim estaria promovendo a transferência de informações a partir da imagem, reforçando a comunicação através das fotos e não através do texto. O que buscamos em Antropologia Visual é esta eficiência da imagem em transmitir o conhecimento, a imagem que dá conta da complexidade do fenômeno se sobrepondo ao texto.

Em “Observações Visuais Reflexivas 1”, Guran realizou algumas combinações entre as imagens. Ele as dispôs formando 4 dípticos, um tríptico e uma foto isolada. Com isto Guran provoca o espectador a estabelecer relações entre as imagens, ou seja, ao considerarmos uma imagem como uma ideia, e uma segunda imagem como outra ideia diferente, a união destas duas imagens formará uma terceira ideia, permitindo ao espectador aprofundar as ideias contidas nas fotos e na relação entre as fotos. Portanto, dentro de um espaço de reflexão acadêmica estaríamos trabalhando com a possibilidade de criar a partir de uma narrativa visual. Ressalta, ainda, que o espaço adequado entre as fotos nos permitirá momentos de "respiro", quando poderemos "limpar" o olhar, fazendo assim, que a informação de uma fotografia (ou conjunto de fotografias) não polua a outra. Este propósito ficará mais claro no próximo tópico, quando estarei apresentando as fotos da exposição.

\section{Visita comentada}

Com a presença do Milton Guran em Porto Alegre, tivemos a oportunidade de fazer uma visita comentada à exposição, logo após a palestra proferida por ele. Esta experiência nos possibilita conversar com o autor detalhes que podem passar 
despercebidos durante a visita. Neste momento o autor explica suas motivações nas escolhas, esclarece a disposição das fotos, apresenta detalhes de sua experiência. Temos a possibilidade de perguntar diretamente nossas dúvidas sobre o trabalho, o que vem a ser muito produtivo na difusão do conhecimento.

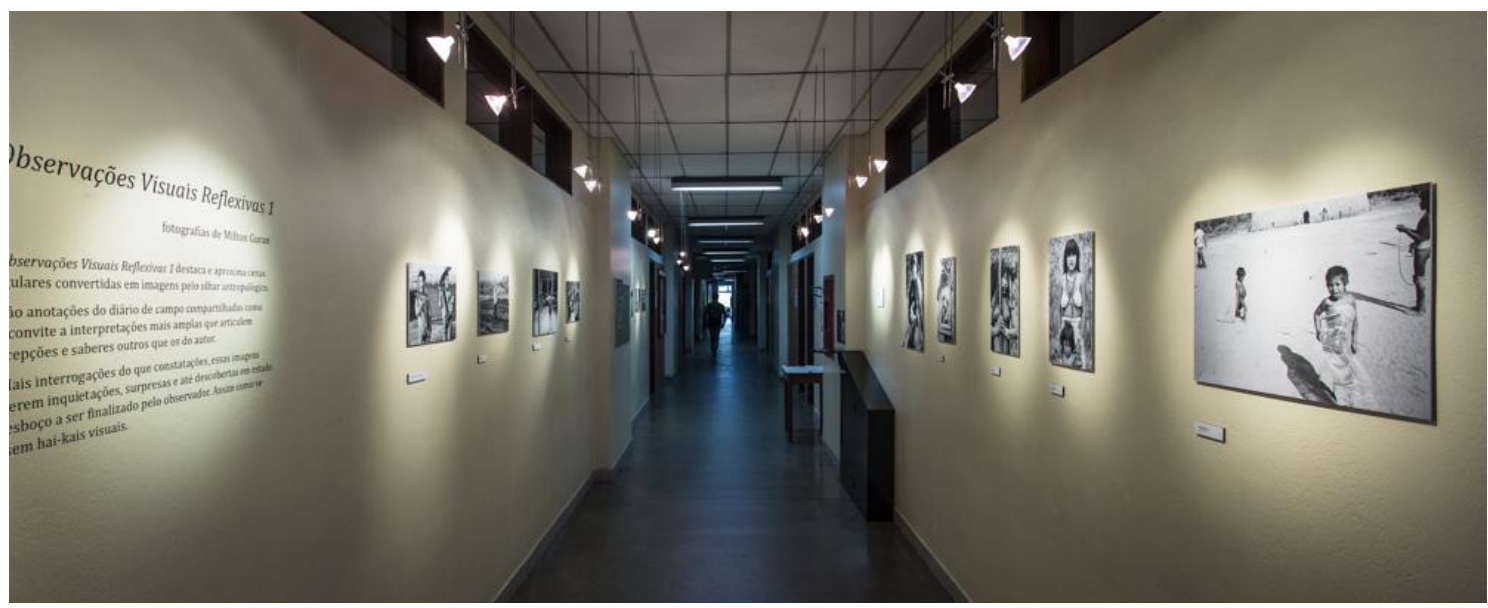

Foto Fabricio Barreto

“Observações Visuais Reflexivas 1 destaca e aproxima cenas singulares convertidas em imagens pelo olhar antropológico.

São anotações do diário de campo compartilhadas como um convite a interpretações mais amplas que articulem percepções e saberes outros que os do autor.

Mais interrogações do que constatações, essas imagens sugerem inquietações, surpresas e até descobertas em estado de esboço a ser finalizado pelo observador. Assim como se fossem hai-kais visuais"

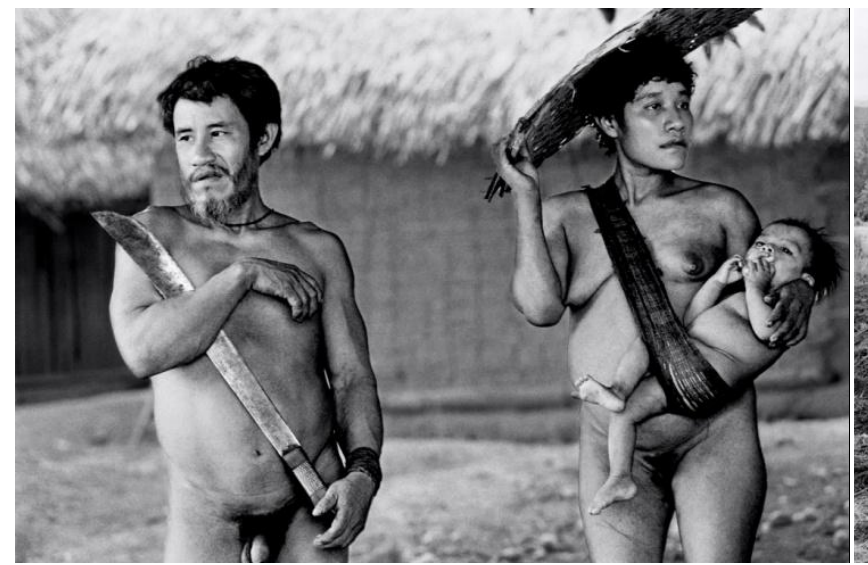

Wokarangma - Arara do Rio Iriri (Pará, 1989)

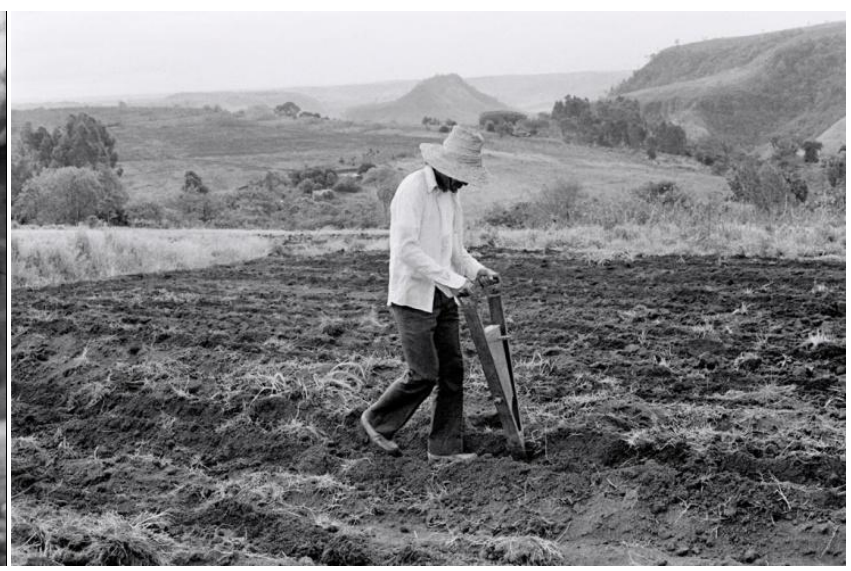

Kaingang (Paraná, 1987)

\footnotetext{
${ }^{4}$ Texto de apresentação da exposição.
} 
Em toda a exposição o autor propõe uma reflexão sobre o contato das comunidades tradicionais com a sociedade complexa. "Estamos falando aqui do entrelaçamento de culturas, de choque de culturas" 5 (Guran), e ainda, "são maneiras de viver nesse planeta que são completamente diferentes e muitas vezes antagônicas". Neste primeiro díptico o contato é demonstrado por intermédio da apropriação dos índios pelas ferramentas do homem branco. O facão, por exemplo, é uma ferramenta muito importante, pois potencializa a atividade do índio dentro da floresta. O que antes na aldeia era um pedaço de pau mais duro é substituído por um objeto cortante. A aproximação com o kaingang do Paraná utilizando uma semeadora vem reforçar esta reflexão de entrelaçamento das culturas e os efeitos que provocam nas comunidades indígenas. Como uma passagem do tempo às avessas, pois a fotografia do kaingang foi realizada antes que a dos wokarangma, percebemos o kaingang muito mais inserido numa condição de sociedade complexa, nos provocando a refletir sobre esta transformação.

A disposição de apresentação dos conjuntos de imagens na galeria sugere um aprofundamento nesta abordagem proposta por Guran. Ele nos diz que "a leitura de uma fotografia será tanto mais rica quanto maior for nossa capacidade de percebemos as nuances de representação desta fotografia”. O próximo díptico evoca o divino e como este está inserido no cotidiano indígena.
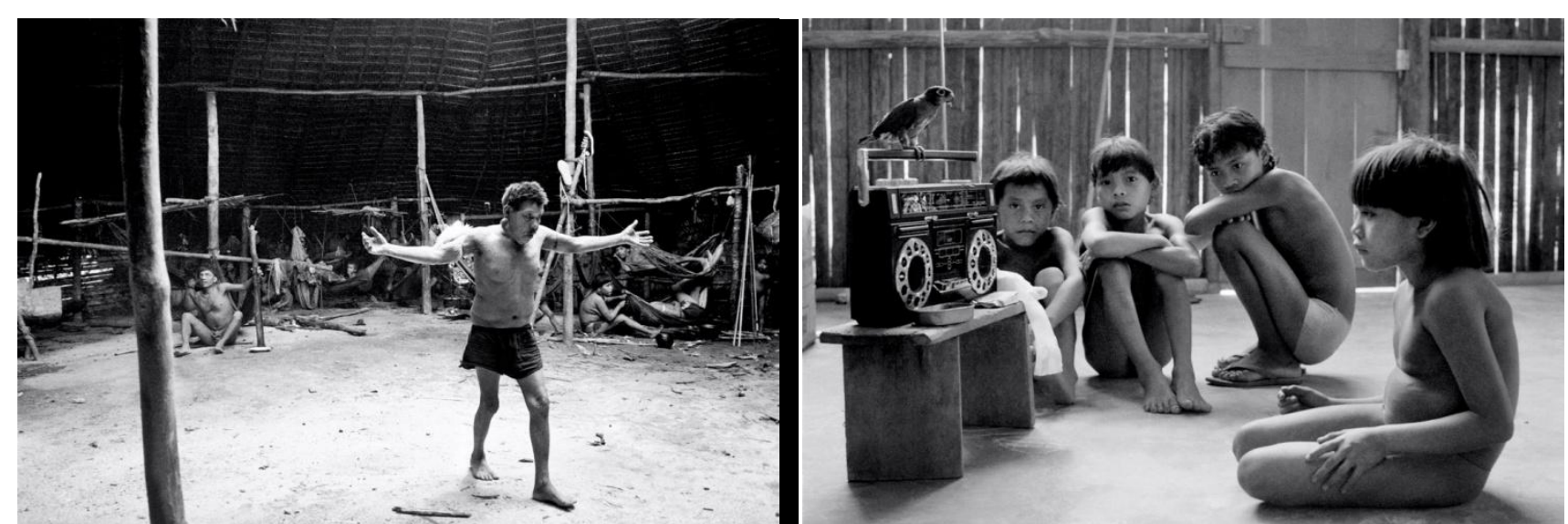

Iniciação xamânica Yanomami - Toototobi (Amazonas, 1991) / Yanomami, Watoriki-teri - Demini (Amazonas, 1991)

\footnotetext{
${ }^{5}$ Texto extraído de gravação realizada durante a visita comentada com Milton Guran. Porto Alegre, 25 de março de 2014.
}

Iluminuras, Porto Alegre, v. 15, n. 35, p. 438-450, jan./jul. 2014 
O ritual é uma prática que está completamente inserida na vida cotidiana do yanomami, o que demonstra uma relação com o divino, com o mágico-religioso, de outra ordem. Podemos observar na fotografia uma iniciação xamânica, em que o mais velho está evocando o divino, enquanto na esquerda vemos o iniciado em transe. Mais ao fundo observamos pessoas que não estão envolvidas diretamente com o ritual, e nos parecem até mesmo alheias ao que acontece no centro da cena. $\mathrm{O}$ ritual faz parte do cotidiano desse povo do Amazonas. Na outra foto temos o mesmo grupo yanomami em outra situação. Estas crianças estão em uma espécie de enfermaria que foi construída na aldeia. O rádio do enfermeiro toca "Entre tapas e beijos" e tem luzes estroboscópicas vermelhas, amarelas e verdes que piscam em sincronia com a música. Imaginando o que é este espetáculo de som e luzes, vemos um índio completamente entregue em postura de reverência e transe frente a este cenário. A questão que se impõe é como essas crianças podem atribuir a mesma força mágico-religiosa do ritual xamânico ao rádio que toca "Entre tapas e beijos" e como esta fricção interétnica será resolvida.

No tríptico temos três imagens dialogando e, ao invés de um ponto e contraponto proposto pelo díptico, há um discurso longo. Enquanto o díptico estabelece uma conversa entre duas imagens, no tríptico esta conversa se desenvolve entre três imagens. A relação entre as imagens proposta por Guran não implica em nenhuma complexa interpretação do que está sendo apresentado. Muito pelo contrário, as imagens transferem uma mensagem direta e neste caso representam três relações diferentes entre os índios yanomami e o branco, ou melhor, a "sociedade nacional envolvente", como ressalta Guran. 


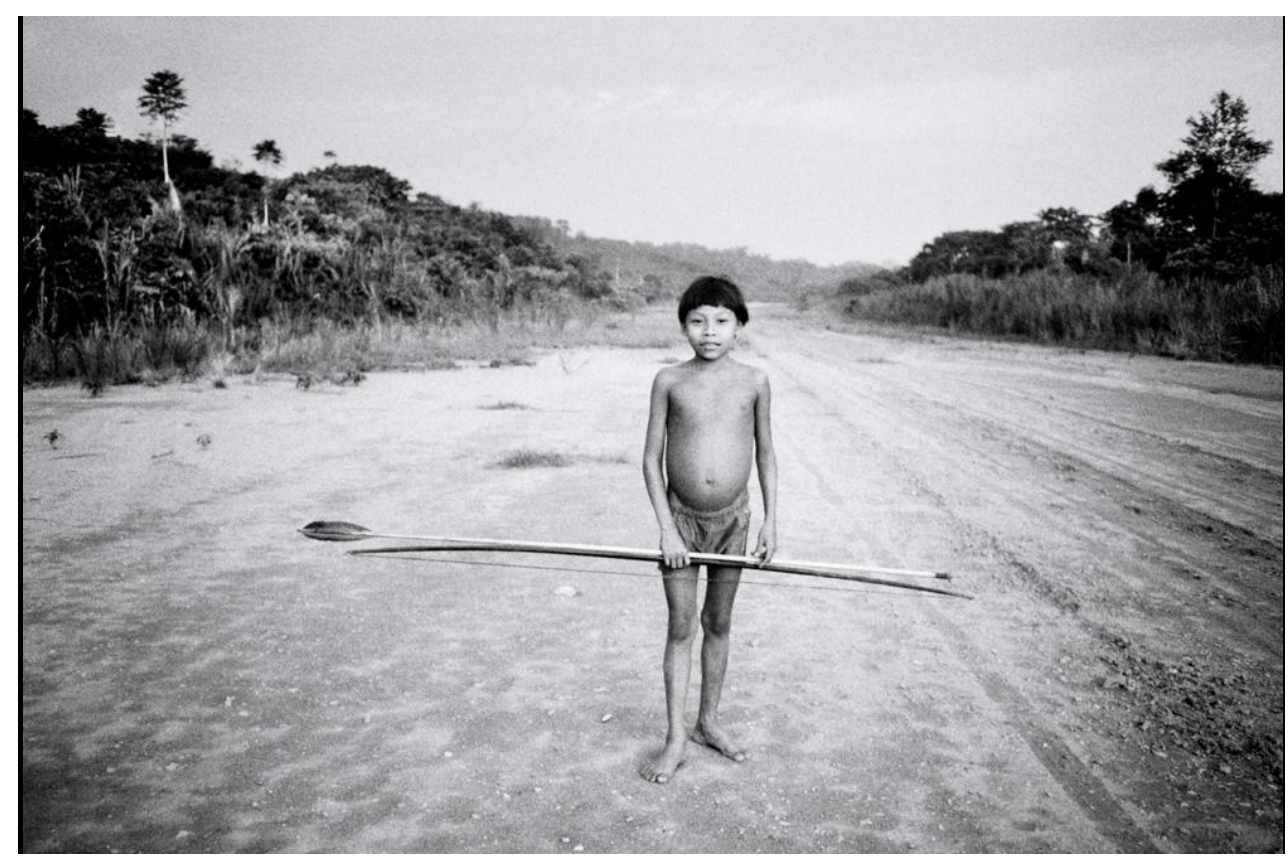

Yanomami - Paapiù (Roraima, 1991)
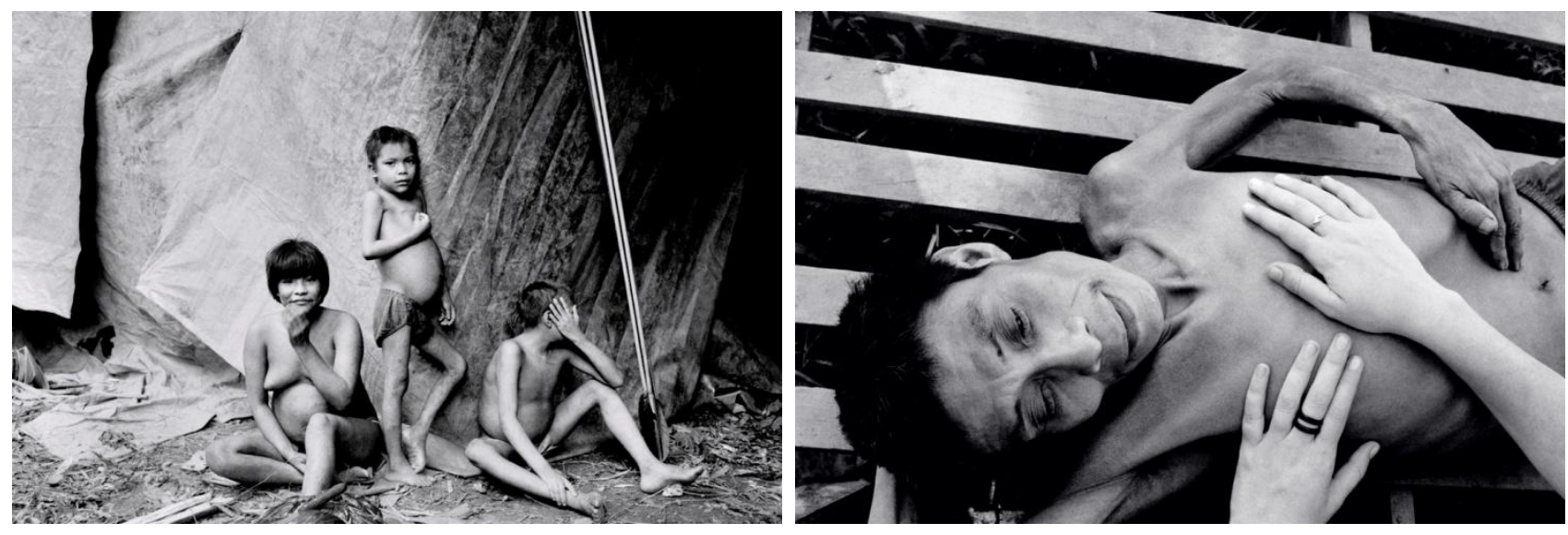

Yanomami - Paapiù (Roraima, 1991) / Yanomami - Paapiù (Roraima, 1991)

$\mathrm{O}$ autor nos conta que a foto onde aparece uma pista clandestina de garimpeiros, está um índio yanomami. Conta-nos também, que neste período, 10\% da população a que faz parte este jovem índio, foi dizimada em situação de genocídio, e ainda assim ele se mantém imponente empunhando seu arco, demonstrando em sua postura a autorização para fotografar. $\mathrm{Na}$ foto seguinte observamos a utilização da lona dos garimpeiros na construção das casas dos yanomami, o que remete a uma favelização. E na terceira foto o yanomami está sendo atendido por uma médica. Ele aponta a área onde dói indicando o baço afetado pela malária, deitado em um estrado levado pelos garimpeiros. Nas "mãos que curam”, observamos uma aliança de côco e uma aliança com um brilhante, nos rementendo a uma mulher de classe média alta. Essas três fotos 
formam um discurso, elas falam uma mesma coisa. A invasão de garimpeiros nas áreas ocupadas pelos índios foi extremamente predatória a essas comunidades tradicionais. Junto com os garimpeiros chegou também a malária, afetando radicalmente a saúde e as condições de sobrevivência dos indígenas.

O próximo díptico contrapõe a realidade da mãe afetada pela malária com seu filho no colo e a representação da mãe orgulhosa. Guran remete a primeira imagem ao arquétipo da mater dolorosa, a mãe sofredora, e a segunda imagem a mater speciosa, a mãe formosa, orgulhosa, ambas representações judaico-cristãs ocidentais. Se por um lado temos a mãe yanomami doente enfrentando a invasão civilizatória dos garimpeiros, de outro temos a mãe rainha com seu filho príncipe, e futuro rei, aproximando a natureza divina do poder real.
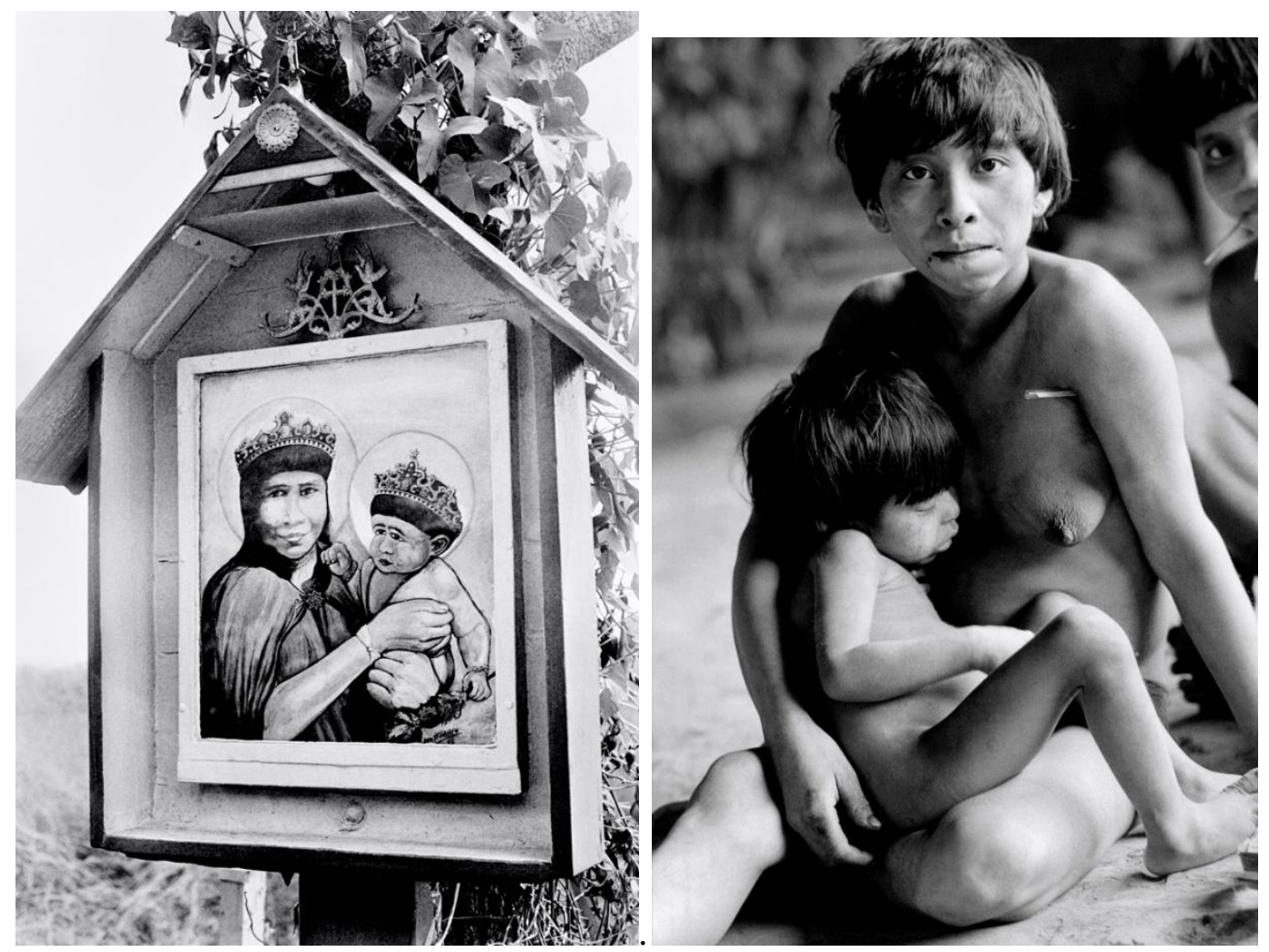

Yanomami - Homoxi (Roraima, 1991) / Xavante - Sangradouro (Mato Grosso, 1986)

Milton Guran em hipótese alguma procura fazer transparecer nesta coleção de imagens uma realidade do índio que não existe mais. Não vamos ver em suas fotos aquela idealização do índio como um selvagem em seu estado natural e intocado. Como fotógrafo documentarista e fiel à convicção de aproximar seu espectador a uma 
realidade fática, apresenta-nos imagens contundentes de seu convívio com estas tribos. No díptico seguinte, os retratos de índias marubo mais uma vez evidenciam a presença da sociedade complexa nas suas vidas. Em um dos retratos a evidência está no relógio digital utilizado pela índia marubo. No outro retrato, Guran nos conta que foi solicitado por um índio que fotografasse sua família. A surpresa de Guran foi a índia marubo vestir um sutiã para posar para a fotografia. Estas roupas são distribuídas pelos missionários, e usá-las representa importância na comunidade.

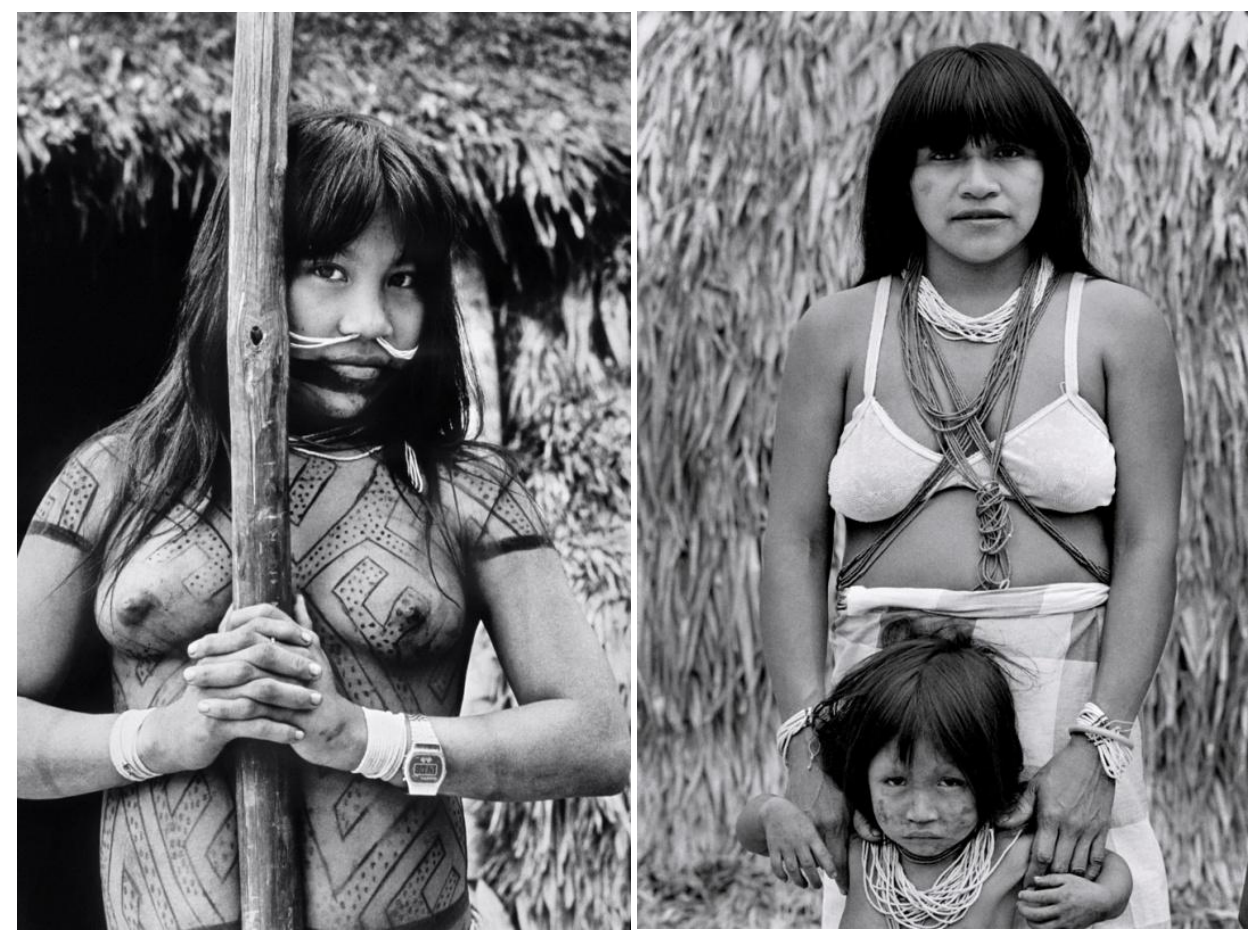

Marubo (Amazonas, 1989) Marubo (Amazonas, 1989)

Milton Guran utiliza um conceito que ele chama imagem monumento, defirenciando da imagem documento. A imagem documento registra e descreve uma determinada situação. A imagem monumento tem caráter transcendental e simbólico, ela representa uma situação pela sua dimensão simbólica que sinaliza. Este é o caso da última fotografia da exposição. Ela é uma espécie de síntese da problemática que foi apresentada nesta coleção. O que aparentemente é uma cena cotidiana de uma aldeia kamayura, possui uma dimensão metafórica que nos remete a uma análise crítica de toda uma situação. Foi apresentada sozinha para dar conta da complexidade mágica, simbólica e transcedental que envolve esta imagem. 


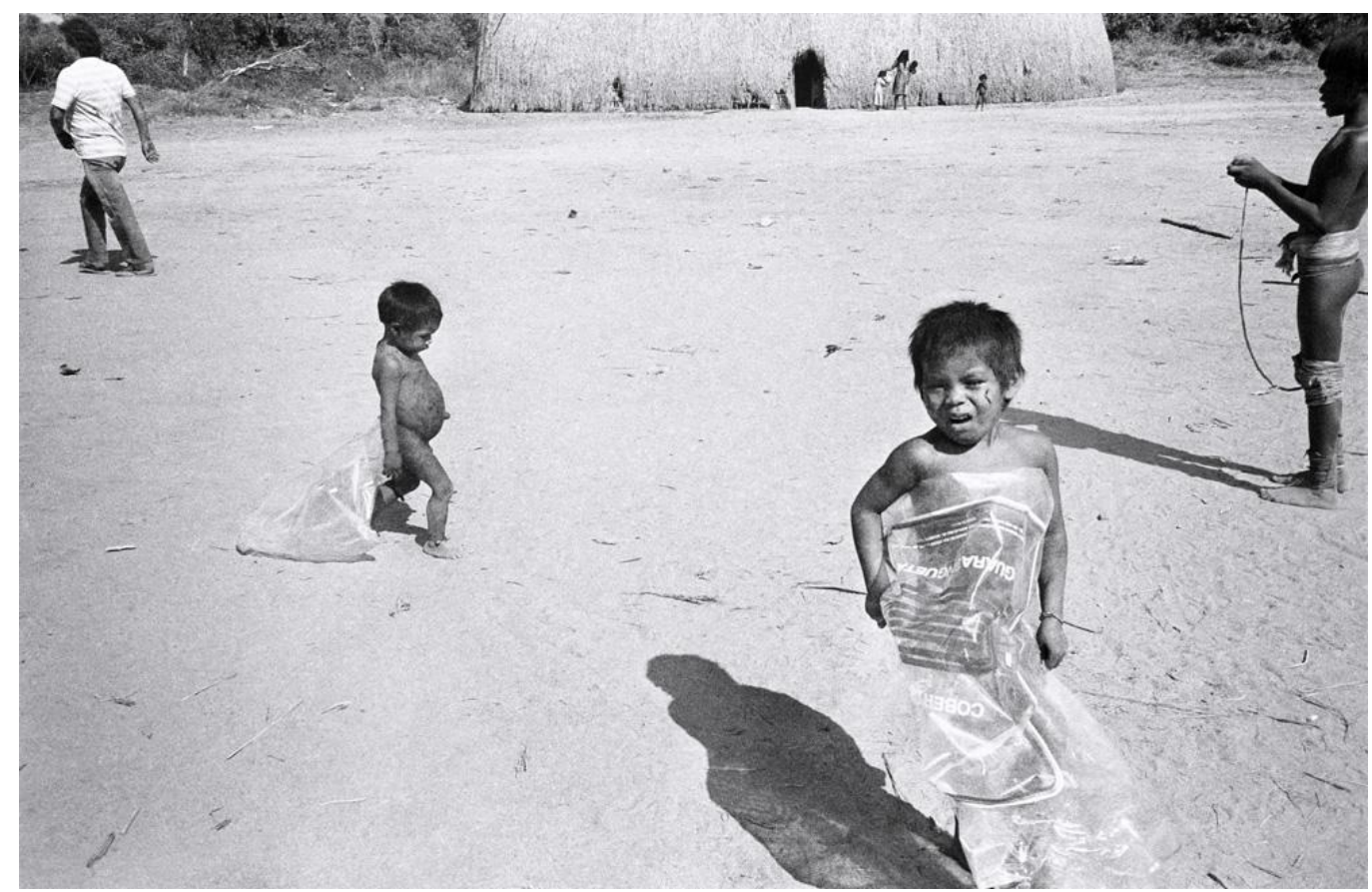

Kamayurá (Xingu, 1984)

Em um enquadramento contra-plongée, no lado direito da fotografia, está um indío kamayura em estado pleno de sua cultura, com sua indumentária tradicional, nu, com o corpo pintado, amarrando sua joelheira. A sombra deste índio se projeta para a criança que está em $1^{\circ}$ plano. Ela já não veste uma indumentária tradicional, mas está envolta em um pedaço de plástico. Sua sombra direciona nosso olhar para outro menino cabisbaixo que entra na cena e tem uma aparência doente. Seguindo essa direção do olhar, visualizamos um índio vestindo calça e camisa que sai da fotografia. Esse caminho percorrido pelo olhar está de acordo com o sentido do movimento dos ponteiros do relógio, ou seja, nossa representação do tempo. Esta imagem é o desfecho da narrativa apresentada por Milton Guran.

\section{Conclusão}

Como nos diz Guran, "as imagens são fundamentais para dar conta da complexidade de um fenômemo, ainda que apoiadas por um texto"6. Em Observações Visuais Reflexivas 1, o autor conduz o espectador a uma narrativa que explicita sua intenção em provocar o questionamento a cerca de crenças sobre os índios na

\footnotetext{
${ }^{6}$ Guran, Milton. 2000. "Fotografar para descobrir, fotografar para contar", In: Cadernos de Antropologia e Imagem, Rio de Janeiro, 10(1): 155-165.
} 
atualidade. Apesar das fotos terem sido realizadas há mais de 20 anos, parcela da sociedade ainda cultiva aquele ideal indígena do humano selvagem. Guran, ao invés disso, nos pergunta como resultará esta fricção de culturas, supostamente a cultura da sociedade complexa e de comunidades tradicionais.

Esta coleção traz a tona a oposição universal entre visível e invisível abordada por José Reginaldo Santos Gonçalves ${ }^{7}$. Ele propõe que é a universalidade dessa oposição que permitirá a comparação entre diferentes culturas, implicando necessariamente em "modalidades distintas do olhar". Gonçalves considera "que este órgão não realiza sua função senão por meio de códigos culturais (regimes visuais) específicos". E nos diz ainda que "a visualidade mesma deixa de ser pensada como experiência natural e é mostrada como resultado de uma série de regras variáveis em termos culturais e históricos" (Gonçalves, 57).

Neste sentido, Guran nos oferece uma possibilidade de comparativos e, não fugindo da construção mediada pela cultura do espectador, leva-nos a reconhecer a cultura do personagem fotografado. Essa mediação visual proporciona uma comunicação entre espaço acadêmico e extra-acadêmico, ocupando posição liminar entre um e outro espaço, tornando-se em potente ferramenta de difusão do conhecimento.

\footnotetext{
${ }^{7}$ Gonçalves, José Reginaldo Santos. Coleções, museus, e teorias antropológicas: reflexões sobre o conhecimento etnográfico e visualidade. In: Antropologia dos objetos : coleções, museus e patrimônios / José Reginaldo Santos Gonçalves. - Rio de Janeiro, 2007: 256.
} 